\title{
ASPEK PENGURUSAN PROGRAM LATIHAN DAN KESANNYA TERHADAP KEPUASAN ATLET SEKOLAH SUKAN
}

\author{
MANAGEMENT TRAINING PROGRAMME AND \\ ITS EFFECT ON THE SPORTS SCHOOL ATHLETES' \\ SATISFACTION
}

\author{
ANUAR DIN \\ Faculty of Psychology and Education \\ Universiti Malaysia Sabah \\ SALLEH ABD RASHID \\ School of Human Development \& Technocommunication \\ Universiti Malaysia Perlis \\ MOHD ISHA AWANG \\ School of Education and Modern Languages \\ Universiti Utara Malaysia
}

\begin{abstract}
Abstrak
Kajian ini bertujuan untuk mengenal pasti kesan aspek Pengurusan Program Latihan terhadap kepuasan atlet sekolah sukan. Seramai 206 orang atlet dari dua buah sekolah sukan di Malaysia telah dipilih menggunakan persampelan rawak sebagai responden kajian. Kajian ini ialah satu kajian kuantitatif yang menggunakan kaedah tinjauan untuk menjawab objektif kajian. Satu set soal selidik telah digunakan dalam kajian ini berdasarkan Athlete Satisfaction Questionnaire (ASQ) oleh Reimer dan Chelladurai (1998) sementara bagi Pengurusan Program Latihan Jurulatih (PPLJ) oleh Anuar (2010). Analisis statistic inferens seperti ujian t, Korelasi Pearson dan Regresi Pelbagai digunakan untuk menguji lima hipotesis nol pada aras signifikan $p<0.05$. Program yang digunakan untuk menganalisis data ialah program SPSS versi 20. Dapatan kajian menunjukkan terdapat hubungan yang positif dan signifikan $(r=0.548, p<0.05)$ antara Pengurusan Program Latihan Jurulatih dengan kepuasan atlet. Selain daripada itu, aspek pengetahuan jurulatih, aspek kemudahan dan fasiliti serta aspek program latihan merupakan pengaruh Pengurusan Program Latihan jurulatih yang utama terhadap kepuasan atlet. Para jurulatih perlu merangka program latihan selaras dengan perkembangan Sains Sukan moden tanpa melupakan
\end{abstract}


IJMS 22 (1), 73-95 (2015)

aspek fasiliti dan kemudahan. Teknologi moden dalam fasiliti dan kemudahan harus digunakan oleh jurulatih dan atlet dengan mengurangkan pendekatan secara tradisional.

Kata kunci: Atlet, pengurusan program latihan, jurulatih, fasa, kepuasan.

\section{Abstract}

Purpose - This study is to identify the effects of management training programmes on the satisfaction among the sports schools' athletes.

Design - This study used a survey-based quantitative research design. Subjects [athletes $(n=206)]$ were randomly selected from two sports schools in Malaysia - the Bukit Jalil Sports School in Kuala Lumpur and Bandar Penawar Sports School in Johor. Samples were selected by using purposive, cluster and random sampling. Questionnaires that were used in the study were developed by Reimer and Chelladurai (1997) for Athlete Satisfaction Questionnaire (ASQ), while the questionnaire for Coach Management Training Program (CMTP) was developed by Anuar (2010). This questionnaire has a high acceptance level (the value of Alpha Cronbach for athletes' satisfaction $=0.942$ and the coach management of training programs aspects $=0.967$ ). Inferential statistics such as $t$-test, Pearson correlation and multiple regression were applied to test the five formulated null research hypothesis at a significant level of $p<0.05$. Quantitative analysis software such as the SPPS version 20 was used to analyse the data.

Finding - Results showed that the relationship between the coach management training programme and athletes' satisfaction was also positive and significant $\quad(r=0.548, p<0.05)$. Results also showed that coach knowledge, facilities and training programme aspects were the primary predictor for the coach management of training programme on athletes' satisfaction.

Significance - Coaches need to set up training programmes that is in line with the development of Sports Science on-going knowledge by using the new modern technology to increase the athletes' satisfaction. In addition, it may be necessary for the coach to reduce the traditional approaches during the coach management of training programs.

Keywords: Athlete, management of training programs, coaches, satisfaction, aspect. 


\section{Pengenalan}

Seseorang jurulatih atau pengurus pasukan ketika berinteraksi dengan atlet semasa mengurus program latihan, sama ada ketika offsite competition atau onsite competition memberi kesan terhadap atlet. Kesan yang diperoleh atlet ialah berkadar terus iaitu jika wujud hubungan yang positif dari aspek interaksi antara keperluan dan kehendak jurulatih, pengurus pasukan dengan atlet, maka kepuasan serta prestasi akan meningkat, atlet akan mencapai kejayaan. Sebaliknya jika berlaku hubungan yang negatif antara keperluan dan kehendak jurulatih, pengurus pasukan dengan atlet, maka kepuasan serta prestasi atlet akan merosot. Atlet akan mengalami kegagalan. Proses interaksi antara jurulatih dengan atlet adalah satu komponen yang sangat penting untuk meningkatkan prestasi dan kepuasan seseorang atlet (Gibbons, McConnell, Forster, Riewald, \& Peterson (2003); Frontiera (2006); Serpa, Pataco, \& Santos, 1991).

Atlet ialah individu yang menyertai acara sukan yang mungkin berstatus profesional atau amatur. Individu ini mempunyai kemahiran fizikal contohnya dari segi kekuatan, ketangkasan dan daya tahan. Perkataan atlet sebenarnya berasal dari Yunani yang bermula dengan "athlos" yang bermakna peraduan. Perkataan peraduan ini bermakna bertarung atau beradu kekuatan. Oleh kerana itu, orang yang bertanding dalam sesuatu pertandingan dipanggil atlet (http:// ms.wikipedia.org/wiki/atlet, 2008).

Dalam penyelidikan ini, atlet bermaksud individu sama ada lelaki atau perempuan yang mengambil bahagian dalam acara sukan sama ada sukan individu atau berpasukan di dua buah sekolah iaitu di Sekolah Sukan Bukit Jalil (SSBJ), Kuala Lumpur dan Sekolah Sukan Tunku Mahkota Ismail (SSTMI), Johor.

Robbins dan Rosenfeld (2001) mendefinisikan kepuasan sebagai perkara yang terjadi apabila segala keperluan individu telah dipenuhi dengan tahap kesukaan dan ketidaksukaan yang berhubung rapat dengan seseorang individu. Kepuasan juga merupakan sifat umum yang dimiliki seseorang individu berkaitan perkara yang mereka yakini setelah melakukan sesuatu pengorbanan. Kenyataan ini boleh diselarikan dengan kepuasan atlet. Kepuasan atlet dikaji berdasarkan tujuh aspek daripada 15 subskala ASQ yang telah dibangunkan oleh Reimer dan Chelladurai (1998). Antara tujuh aspek tersebut 
ialah aspek pencapaian individu, aspek pencapaian pasukan, aspek strategi, aspek latihan dan arahan, aspek perpaduan pasukan, aspek dedikasi individu dan aspek rawatan.

Pengurusan bermakna proses perancangan, penyusunan kerja, kepimpinan dan pengawalan, daya usaha anggota organisasi untuk mencapai matlamat yang ditentukan dalam konteks organisasi yang terlibat dengan penyediaan aktiviti, produk atau perkhidmatan sukan dan kecergasan (Chelladurai, 1999). Mohd Salleh (2005) pula menyatakan pengurusan ialah satu proses mencari cara menentukan tanggungjawab dan mengendalikan sumber fizikal dengan merancang, mengorganisasi, memimpin dan mengawal perjalanan pergerakan sukan bagi mencapai objektif organisasi.

Sementara itu, program latihan ialah satu tatacara, prosedur atau panduan yang dihasilkan oleh jurulatih bagi melatih atlet dalam satu tempoh tertentu. Oleh yang demikian, pengurusan program latihan dapat dinyatakan sebagai satu proses yang dirancang oleh jurulatih untuk melatih atlet di bawah kendaliannya dalam satu tempoh yang tertentu. Proses ini bermula daripada fasa persediaan, fasa pertandingan dan fasa transisi. Proses ini bersamaan dengan Wee Eng Hoe (2006) yang menyatakan pengurusan program latihan ini terbahagi kepada tiga peringkat seperti yang telah disenaraikan. Dalam ketiga-tiga fasa tersebut, terdapat empat aspek yang dikaji. Aspek-aspek tersebut ialah aspek program latihan, aspek strategi, aspek fasiliti dan kemudahan, dan aspek pengetahuan jurulatih.

Kepuasan kerja jurulatih dengan pengurusan program latihan yang terancang mempunyai hubungan secara langsung atau tidak langsung yang akan menyebabkan seseorang atlet di bawah kendalian akan merasa puas. Menurut Mallet (2003), jurulatih memainkan peranan yang sangat penting dalam melahirkan atlet dengan kemahiran dan pengetahuan yang diperlukan bagi meningkatkan prestasi atlet dalam sukan yang mereka ceburi. Jurulatih juga mempunyai pengaruh yang sangat besar dalam mewujudkan keseronokan dan kepuasan serta penyertaan berterusan atlet. Hamidreza (2013) telah menjalankan kajian berkaitan gaya kepimpinan jurulatih, komitmen sukan terhadap kepuasan atlet pemain bola sepak sekolah menengah di Iran. Dapatan kajian beliau menunjukkan terdapat hubungan yang positif antara gaya kepimpinan jurulatih, komitmen sukan dengan kepuasan pemain bola sepak. Gaya kepimpinan dan kepuasan pemain yang semakin bagus akan meningkatkan komitmen pemain dalam sukan. Oleh yang demikian, pengurusan program latihan yang 
dikendalikan seseorang jurulatih haruslah dapat memuaskan hati atlet sama ada program latihan semasa fasa transisi, fasa persediaan dan fasa pertandingan.

Kepuasan seseorang atlet dalam latihan atau kejohanan yang disertainya bukan sahaja dipengaruhi faktor diri atlet sendiri tetapi juga oleh faktor lain. Contohnya kejayaan Lee Chong Wei dan Rashid Sidek yang pernah menjadi pemain nombor satu dunia dalam acara badminton (BWF, 2010), kemenangan Shalin Zulkifli dalam acara tenpin boling dan kecemerlangan Nicol Ann David mempertahankan kedudukannya sebagai pemain nombor satu dunia dalam acara skuasy banyak dipengaruhi faktor kesungguhan pemain itu sendiri, dorongan dan motivasi daripada pakar psikologi sukan (Duda, \& Nicholls, 2006; Shaharudin, 2005) dan pengurusan program latihan serta gaya kepimpinan yang diguna pakai oleh jurulatih (Chelladurai, 1984) semasa latihan sama ada offsite competition dan onsite competition. Kejayaan demi kejayaan dan kekalahan demi kekalahan yang diperoleh pemain beregu badminton negara Koo Kien Keat dan Tan Boon Heong yang mendapat pingat Emas di Sukan Asia, Doha, 2006, muncul sebagai Juara Terbuka Malaysia 2007, Juara All England 2007, Juara Terbuka Switzerland 2007 dan Juara Terbuka Denmark 2007, tewas di Sukan Olimpik 2008 (BWF, 2010) juga dipengaruhi gaya kepimpinan jurulatih, kepuasan kerja jurulatih dan pengurusan program latihan jurulatih (Anuar, 2010).

Selain daripada itu, jurulatih seharusnya mempunyai cara dalam menangani masalah yang dihadapi atlet. Jurulatih seharusnya mempunyai kepakaran dalam membantu atlet untuk mencapai kepuasan dan pencapaian dalam kejohanan yang disertainya. Idea dan strategi jurulatih telah dapat dibuktikan seperti gaya kepimpinan yang dilakukan oleh Datuk Misbun Hj Sidek iaitu jurulatih perseorangan negara bagi Lee Chong Wei dan Wong Mei Chew serta Rexy Mainaky jurulatih beregu negara bagi Koo Kien Keat dan Tan Boon Heong serta Mohd Zakry Latif dan Mohd Fairuzizuan Tazari. Sementara itu Gert, Tanja, Filip, Jeroen, Wouter dan Marten (2007) menyatakan matlamat utama jurulatih dalam melatih atlet remaja adalah untuk meningkatkan prestasi mereka dari segi teknikal, taktikal dan fizikal. Antara kepakaran yang perlu dikuasai seseorang jurulatih ialah gaya kepimpinannya semasa melatih atlet. Terdapat dua faktor yang sangat berpengaruh bagi mencapai tahap kepuasan atlet dalam sukan, antaranya ialah faktor intrinsik dan faktor ekstrinsik. Walaupun faktor intrinsik, yang merupakan faktor dalaman diri atlet, boleh memberikan kepuasan dalam sukan, tetapi faktor ekstrinsik 
juga menyumbang kepada tahap kepuasan atlet dalam sukan. Oleh hal yang demikian, faktor seperti dimensi latihan dan arahan dalam gaya kepimpinan jurulatih perlu diberikan perhatian oleh jurulatih semasa melaksanakan program latihan dalam meningkatkan tahap kepuasan atlet dalam sukan (Anuar, \& Dolorine, 2013).

\section{Pernyataan Masalah}

Semasa mengendali dan menguruskan sesebuah pasukan sama ada di peringkat sekolah, daerah, negeri dan negara, seseorang jurulatih mahupun pengurus pasukan seharusnya mempunyai gaya kepimpinan yang tersendiri. Gaya kepimpinan jurulatih, kepuasan kerja jurulatih dan pengurusan program latihan jurulatih dalam latihan penting kerana ini merupakan salah satu faktor untuk atlet mencapai kepuasan dan kejayaan yang cemerlang dalam kejohanan yang disertainya (Abd Hair, Azimi, Jegak, Asma, \& Rahmah, 2006).

Selain daripada itu, atlet juga tidak berpuas hati terhadap aspek pengurusan program latihan yang dikendalikan oleh jurulatih. Antara aspek yang menyebabkan atlet kurang puas hati ialah aspek kemahiran dan pengetahuan jurulatih, aspek kemudahan dan fasiliti, aspek program latihan, aspek kewangan, aspek pengurusan persatuan dan organisasi serta aspek kewangan. Faktor ini merupakan antara faktor yang menyebabkan atlet tidak berpuas hati dan perkara ini dipersetujui oleh Gibbons et al. (2003), Greenleaf, Gould, \& Dieffenbach (2003) yang menyatakan atlet Sukan Olimpik Amerika Syarikat tidak berpuas hati terhadap pengurusan program latihan yang dikendalikan oleh jurulatih mereka.

Di samping itu, masalah yang menyebabkan atlet juga tidak berpuas hati ialah faktor yang berkaitan dengan kepuasan kerja jurulatih. Walaupun faktor ini merupakan faktor bukan secara langsung, tetapi faktor ini juga memberi kesan terhadap kepuasan atlet. Jurulatih yang berpuas hati terhadap pekerjaannya dapat melaksanakan program latihan dengan berkesan dan ini secara tidak langsung memberi kesan yang positif terhadap atlet di bawah kendaliannya. Kajian yang dijalankan oleh Davies, Bloom dan Salmela (2005) menunjukkan terdapat jurulatih yang tidak berpuas hati terhadap tugas pentadbiran yang mengganggu mereka semasa mengendalikan program latihan bersama atlet. Di samping itu, terdapat juga jurulatih yang tidak berpuas hati dengan persekitaran kerja mereka seperti 
kajian yang dijalankan oleh Jin Ho Choi (2006) yang menunjukkan bahawa persekitaran kerja merupakan faktor yang paling kritikal terhadap kepuasan kerja jurulatih.

Selain daripada itu, faktor pengurusan program latihan yang dijalankan oleh jurulatih dapat meningkatkan kepuasan atlet atau menyebabkan prestasi dan kepuasan atlet menurun. Pengurusan program latihan yang tidak terancang juga menyebabkan prestasi dan kepuasan atlet merosot. Menurut Wee Eng Hoe (2006) pengurusan program latihan memberi panduan asas kepada seseorang jurulatih untuk membuat keputusan, memberi arahan dan membantu atlet mencapai prestasi dan kepuasan diri. Pengurusan program latihan dalam meningkatkan kepuasan atlet selalunya dibahagikan kepada tiga fasa. Menurut Bompa (1999), terdapat tiga fasa dalam program latihan sukan iaitu fasa persediaan, fasa pertandingan dan fasa transisi. Dalam fasa persediaan dibahagikan pula kepada dua iaitu fasa persediaan am dan fasa persediaan spesifik. Fasa pertandingan pula dibahagikan kepada dua iaitu fasa prapertandingan dan fasa pertandingan. Kesemua fasa ini bermula dengan proses pengurusan program latihan yang dirancang oleh jurulatih.

Terdapat atlet yang tidak menggemari fasa persediaan kerana pada pandangan atlet, fasa ini ialah satu fasa yang membebankan kerana setelah lama berehat (di luar musim pertandingan) mereka terpaksa melakukan aktiviti fizikal yang mempunyai intensiti tinggi. Menurut Bompa (1999) fasa ini merupakan satu fasa yang seharusnya mengambil masa yang lama, iaitu lima bulan bagi satu tempoh setahun dalam program latihan. Walau bagaimanapun, terdapat segelintir atlet yang menggemari fasa ini kerana fasa ini akan menyebabkan mereka kembali kepada fizikal mereka sebagai atlet. Begitu juga dengan fasa pertandingan, terdapat atlet yang tidak menggemarinya kerana terpaksa melalui latihan yang membebankan seperti fizikal, taktikal, teknikal, psikologi dan sebagainya. Sebaliknya terdapat atlet yang seronok dengan aktiviti ini. Seterusnya terdapat juga atlet yang kurang gemar dengan fasa transisi, iaitu satu fasa yang menyebabkan mereka rasa bosan kerana sudah terbiasa dengan fasa yang memerlukan fokus yang tinggi. Fasa ini dilaksanakan oleh atlet lebih kurang sebulan (Bompa, 1999). Oleh sebab itu, pengurusan program latihan memainkan peranan penting dalam menarik minat atlet agar mereka seronok dan merasa puas terhadap latihan yang dirancang. 
Selain itu, kadangkala jurulatih yang dilantik atau dipilih mempunyai pengalaman sebagai pemain tetapi mempunyai asas yang sangat kurang dalam penekanan dari aspek Sains Sukan seperti aspek pengetahuan. Ini menyebabkan terdapat segelintir atlet merasa tidak puas hati yang menyebabkan prestasi mereka merosot. Selain itu, terdapat juga jurulatih yang mempunyai asas kejurulatihan yang baik tetapi tidak mempunyai gaya kepimpinan dan tidak berpuas hati terhadap kerja yang akhirnya menyebabkan prestasi dan kepuasan atlet menurun. Kenyataan ini bertepatan dengan dapatan kajian yang dilakukan oleh Cakioglu (2003) yang menyatakan perkara yang hampir sama berlaku di Turki, iaitu kurangnya penekanan antara gaya kepimpinan dengan kepuasan atlet. Di samping itu, kekurangan ilmu pengetahuan dalam bidang kejurulatihan terutamanya dalam Sains Sukan juga merupakan salah satu faktor yang menyebabkan atlet kurang berpuas hati terhadap prestasi mereka. Keadaan ini berlaku kerana jurulatih yang mempunyai kemahiran dan juga pengetahuan dalam bidang Sains Sukan dapat mengenal pasti dan memperbaiki kelemahan yang ada pada atlet yang mereka latih (Ithnin, 2005). Saranan yang dinyatakan oleh Ithnin Mahadi (2005) menyebabkan pengkaji tertarik dan berminat untuk membuat penyelidikan agar satu dapatan sebenarnya dapat dihasilkan dan bukannya dari pandangan atau pemerhatian sahaja.

Wee Akina dan Shabeshan (2014) telah menjalankan kajian ke atas atlet sekolah menengah di Malaysia berkaitan gaya kepimpinan jurulatih yang diminati. Atlet terdiri daripada mereka yang berumur 13 hingga 16 tahun. Dapatan kajian mereka mendapati atlet lebih menggemari gaya kepimpinan jurulatih bagi dimensi maklum balas positif. Hal ini menunjukkan bahawa atlet yang kebajikan mereka sentiasa dijaga pasti akan berasa puas hati dan seronok. Kesannya membolehkan mereka berasa yakin apabila mengikuti program latihan di bawah bimbingan jurulatih.

Kesimpulannya, kepuasan atlet dalam sukan yang diceburinya sama ada individu atau sukan berpasukan bukan sahaja disebabkan oleh faktor intrinsik atlet tetapi juga dipengaruhi faktor eksternal seperti gaya kepimpinan jurulatih, kepuasan kerja jurulatih dan pengurusan program latihan jurulatih yang berkesan.

\section{Objektif Kajian}

Secara umumnya, kajian ini bertujuan mengenal pasti pengurusan program latihan jurulatih dapat memberikan kesan ke atas kepuasan 
atlet sekolah sukan. Objektif kajian ini juga memfokuskan kepada mengenal pasti sama ada terdapat perbezaan, hubungan dan atau pengaruh sama ada secara langsung atau tidak langsung pemboleh ubah pengurusan program latihan jurulatih dengan kepuasan atlet. Objektif ini diperincikan kepada tiga objektif seperti berikut:

1. Mengenal pasti sama ada terdapat perbezaan pengurusan program latihan jurulatih berdasarkan demografi atlet.

2. Melihat hubungan antara pengurusan program latihan jurulatih dengan kepuasan atlet sekolah sukan.

3. Mengenal pasti faktor yang paling berpengaruh pengurusan program latihan jurulatih terhadap kepuasan atlet sekolah sukan.

\section{Hipotesis Kajian}

Berdasarkan objektif kajian, terdapat lima hipotesis kajian yang telah dikenal pasti untuk diuji. Dalam kajian ini, aras signifikan 0.05 digunakan bagi tujuan melaksanakan data statistik inferens. Selain itu, hipotesis nol juga digunakan dalam kajian ini. Hipotesis-hipotesis nol tersebut adalah:

$\mathrm{H}_{01}$ : Tidak terdapat perbezaan yang signifikan antara pengurusan program latihan jurulatih mengikut fasa berdasarkan jantina atlet.

$\mathrm{H}_{02}$ : Tidak terdapat hubungan yang signifikan antara pengurusan program latihan jurulatih dengan kepuasan atlet.

$\mathrm{H}_{03}$ : Tidak terdapat pengaruh yang signifikan pengurusan program latihan jurulatih bagi fasa persediaan terhadap kepuasan atlet.

$\mathrm{H}_{04}$ : Tidak terdapat pengaruh yang signifikan pengurusan program latihan jurulatih bagi fasa pertandingan terhadap kepuasan atlet.

$\mathrm{H}_{05}$ : Tidak terdapat pengaruh yang signifikan antara pengurusan program latihan jurulatih fasa transisi terhadap kepuasan atlet.

\section{Metodologi Kajian}

Kajian ini ialah satu penyelidikan yang berbentuk deskriptif, perbandingan, hubungan dan pengaruh sebagai kajian untuk melihat hubungan antara satu pemboleh ubah dengan pemboleh ubah yang lain. Reka bentuk kajian ialah kajian tinjauan berbentuk 
secara kuantitatif, bukan eksperimen yang menggunakan soal selidik sebagai instrumen kajian. Selain itu, teknik pengumpulan data menggunakan soal selidik sesuai digunakan kerana teknik ini bersesuaian dengan reka bentuk yang dipilih, selain itu kajian ini sesuai untuk mendapatkan maklumat tentang fakta (Mohd Najib, 2000; Chua Yan Piaw, 2006).

Berpandukan jadual penentuan saiz pensampelan Krejie dan Morgan (1970), populasi kajian bagi kedua-dua buah sekolah sukan adalah 871 orang iaitu 467 orang murid daripada Sekolah Sukan Bukit Jalil, Kuala Lumpur (SSBJ) dan 404 orang murid daripada Sekolah Sukan Bandar Penawar, Johor (SSBP) (Pendaftaran Murid SSBJ dan SSBP tahun 2009). Daripada jumlah berkenaan, seramai 260 orang dipilih sebagai subjek kajian, iaitu 130 (50\%) subjek kajian daripada Sekolah Sukan Bukit Jalil, Kuala Lumpur manakala 50 peratus lagi subjek kajian dari Sekolah Sukan Bandar Penawar, Johor. Pemilihan mereka sebagai responden kajian menerusi pensampelan bertujuan dan diikuti dengan persampelan rawak mudah.

Instrumen bagi kajian ini ialah soal selidik. Satu set soal selidik untuk atlet dibahagikan kepada 3 bahagian iaitu Bahagian A, B dan C. Bahagian A berkaitan biodata subjek seperti jantina, umur, jenis sukan, kategori sukan, peringkat penglibatan, jumlah masa berlatih dan pengaruh individu. Bahagian B pula berkenaan soal selidik tentang Kepuasan Atlet sementara Bahagian C pula adalah untuk soal selidik Pengurusan Program Latihan Jurulatih.

Bahagian B menggunakan Soal Selidik Kepuasan Atlet (Athlete Satisfaction Questionnaire) yang telah dibangunkan oleh Riemer dan Chelladurai (1998). Dalam soal selidik ini terdapat 56 item dan telah dibahagikan kepada 15 subskala iaitu pencapaian individu, pencapaian pasukan, memanfaatkan kemampuan, strategi, rawatan secara personal, latihan dan arahan, sumbangan dan tugas ke atas pasukan, sumbangan sosial berpasukan, etika pasukan, perpaduan pasukan, dedikasi individu, bajet, mempunyai panel perubatan, pembantu penyokong akademik, dan ejen luar. Dalam kajian ini hanya tujuh subskala sahaja yang digunakan iaitu aspek pencapaian individu, aspek pencapaian pasukan, aspek strategi, aspek latihan dan arahan, aspek perpaduan pasukan, aspek dedikasi individu dan aspek rawatan secara personal. Kesemua item dalam soal selidik ASQ ini adalah sebanyak 35. Subjek perlu menjawab setiap soalan dengan menggunakan Skala Likert lima mata iaitu: 


$\begin{array}{ll}1 & \text { Sangat tidak setuju } \\ 2 & \text { Tidak setuju } \\ 3 & \text { Tidak pasti } \\ 4 & \text { Setuju } \\ 5 & \text { Sangat setuju }\end{array}$

Nilai kebolehpercayaan Soal Selidik Kepuasan Atlet (ASQ) berdasarkan kepada kajian Reimer dan Chelladurai (1998) dan Reimer dan Toon (2001) adalah pada alpha cronbach antara 0.78 hingga 0.99 bagi setiap subskala. Atlet juga diminta menjawab soal selidik berkaitan dengan pengurusan program latihan yang dilaksanakan oleh jurulatih di Bahagian C. Sebanyak 30 soalan diberikan kepada atlet subskala dibahagikan kepada empat aspek iaitu aspek strategi jurulatih mempunyai enam item, aspek program latihan mempunyai 11 item, aspek fasiliti dan kemudahan mempunyai sembilan item serta aspek pengetahuan mempunyai empat item. Nilai kebolehpercayaan soal selidik pengurusan program latihan jurulatih adalah pada alpha cronbach 0.93 hingga 0.95 iaitu aspek strategi jurulatih (0.94), aspek program latihan (0.93), aspek fasiliti dan kemudahan (0.95), serta aspek pengetahuan (0.94).

Semua item yang dibina adalah berdasarkan kepada laporan dan kajian yang telah dilakukan oleh Greenleaf, Gould dan Dieffenbach (2001), Gibbons et al. (2003), Park, Bestmann dan Yean Sub Lim (1999) dan Bompa (1999). Bagi mendapatkan jumlah responden seperti yang disasarkan untuk atlet, temu janji telah dilakukan terlebih dahulu melalui perbualan telefon dengan kedua pentadbir sekolah SSBJ dan SSBP. Setelah itu, kunjungan dan lawatan ke kedua-dua buah sekolah dilakukan dengan membuat temu janji terlebih dahulu bagi membolehkan subjek yang terlibat dapat hadir dan juga tidak bertembung dengan sebarang kejohanan yang disertai oleh subjek. Penerangan yang terperinci disampaikan kepada pentadbir dan juga subjek kajian supaya mereka memahami tujuan kehadiran pengkaji ke sekolah mereka, tujuan kajian, kepentingan kajian, kepentingan maklum balas subjek serta jaminan kesulitan soal selidik yang telah dilengkapkan (Gay, \& Airasian, 2003).

Setelah borang soal selidik diletakkan di atas meja bersama alat tulis di dalam dewan kuliah sekolah masing-masing, semua subjek dibenarkan masuk ke dalam dewan kemudian diikuti penerangan yang terperinci berkaitan tentang tujuan kajian, cara menjawab soalan dari setiap item dalam semua instrumen. Subjek kajian juga diberitahu bahawa segala maklum balas yang mereka berikan di dalam 
borang soal selidik adalah sulit dan rahsia dan hanya untuk tujuan penyelidikan ini sahaja. Oleh sebab itu, pada setiap naskhah borang soal selidik dilampirkan surat rasmi yang menerangkan tujuan kajian dilaksanakan. Subjek kajian diminta menandakan (/) pada borang soal selidik yang diedarkan selain menjawab soalan berkaitan demografi subjek. Masa yang diberikan ialah selama 45 minit. Subjek yang telah melengkapkan borang soal selidik dibenarkan meninggalkan dewan serta borang soal selidik dikumpulkan.

\section{Dapatan Kajian}

Berdasarkan Jadual 1, ujian-t tidak bersandar telah digunakan untuk melihat perbezaan pengurusan program latihan jurulatih mengikut fasa berdasarkan jantina atlet. Terdapat tiga fasa dalam pengurusan program latihan jurulatih iaitu fasa persediaan, fasa pertandingan dan fasa transisi.

\section{Jadual 1}

Perbezaan Pengurusan Program Latihan Jurulatih Mengikut Fasa Berdasarkan Jantina

\begin{tabular}{|c|c|c|c|c|c|c|c|}
\hline $\begin{array}{l}\text { Pengurusan Program } \\
\text { Latihan Jurulatih-Fasa }\end{array}$ & Jantina & $N$ & $M$ & $S D$ & $t$ & $d f$ & $p$ \\
\hline Fasa & Lelaki & 104 & 4.166 & 0.591 & 0.707 & 204 & 0.480 \\
\hline Persediaan & Perempuan & 102 & 4.102 & 0.712 & & & \\
\hline Fasa & Lelaki & 104 & 4.154 & 0.510 & 0.374 & 182.829 & 0.709 \\
\hline Pertandingan & Perempuan & 102 & 4.122 & 0.712 & & & \\
\hline Fasa & Lelaki & 104 & 3.985 & 0.638 & 0.334 & 204 & 0.739 \\
\hline Transisi & Perempuan & 102 & 3.953 & 0.762 & & & \\
\hline Keseluruhan Fasa & Lelaki & 104 & 4.102 & 0.517 & 0.503 & 186.127 & 0.616 \\
\hline $\begin{array}{l}\text { Pengurusan } \\
\text { Program Latihan } \\
\text { Jurulatih }\end{array}$ & Perempuan & 102 & 4.059 & .698 & & & \\
\hline
\end{tabular}

Dapatan kajian menunjukkan bahawa tidak terdapat perbezaan yang signifikan dalam min fasa persediaan, fasa pertandingan dan fasa transisi serta keseluruhan fasa pengurusan program latihan jurulatih berdasarkan jantina atlet. Oleh hal yang demikian, hipotesis $\mathrm{H}_{\mathrm{o}}$ yang menyatakan tidak terdapat perbezaan yang signifikan antara 
pengurusan program latihan jurulatih mengikut fasa berdasarkan jantina atlet diterima.

\section{Jadual 2}

Korelasi Pearson antara Pengurusan Program Latihan Jurulatih dengan Kepuasan Atlet

\begin{tabular}{llc}
\hline $\begin{array}{l}\text { Pengurusan program Latihan } \\
\text { Jurulatih }\end{array}$ & Kepuasan Atlet \\
\hline $\begin{array}{l}\text { Pengurusan Program Latihan } \\
\text { Jurulatih }\end{array}$ & Korelasi Pearson & $0.548\left(^{* *}\right)$ \\
& Sig. (2-hujung) & 0.000 \\
\hline $\mathrm{n}=206$ & \\
$* *$ Aras Signifikan: $\mathrm{p}<0.01$ (2-hujung) &
\end{tabular}

Berdasarkan Jadual 2, dapatan kajian menunjukkan bahawa terdapat hubungan yang positif dan signifikan antara gaya kepimpinan jurulatih dalam kalangan atlet dengan kepuasan atlet $(r=0.586, p$ $<0.05)$ dan kekuatan korelasi bagi kedua-dua pemboleh ubah ini adalah sederhana. Sementara itu, dapatan kajian juga mendapati terdapat hubungan yang positif dan signifikan antara pengurusan program latihan jurulatih dengan kepuasan atlet $(r=0.548, p<$ 0.05) dan kekuatan korelasi antara kedua-dua pemboleh ubah ini adalah sederhana. Oleh sebab yang demikian, hipotesis $\mathrm{H}_{\mathrm{o} 2}$ yang menyatakan tidak terdapat hubungan yang signifikan antara gaya kepimpinan jurulatih dengan pengurusan program latihan jurulatih dengan kepuasan atlet adalah ditolak.

\section{Jadual 3}

Analisis Regresi Stepwise Pengurusan Program Latihan Jurulatih Fasa Persediaan Terhadap Kepuasan Atlet

\begin{tabular}{|c|c|c|c|}
\hline $\begin{array}{l}\text { Pengurusan program Latihan } \\
\text { Jurulatih Fasa Persediaan }\end{array}$ & $\beta$ & $t$ & $p$ \\
\hline Aspek Pengetahuan & 0.486 & 7.950 & 0.000 \\
\hline Aspek Fasiliti \& Kemudahan & 0.239 & 2.413 & 0.017 \\
\hline $\begin{array}{l}\text { Maklumat: } \\
\text { Aspek Pengetahuan: } \\
{ }^{*} p<0.05 \\
R^{2}=0.237 \\
\mathrm{AR}^{2}=0.233 \\
F \quad=63.210 \\
p=0.000\end{array}$ & \multicolumn{3}{|c|}{$\begin{array}{l}\text { Aspek Fasiliti dan } \\
{ }^{*} p<0.05 \\
R^{2}=0.258 \\
\mathrm{AR}^{2}=0.251 \\
F \quad=35.262 \\
p \quad=0.000\end{array}$} \\
\hline
\end{tabular}


Berdasarkan Jadual 3, pemboleh ubah kriteria dalam kajian ini ialah kepuasan atlet, manakala pemboleh ubah peramal pula pengurusan program latihan jurulatih bagi fasa persediaan. Fasa persediaan ini dibahagikan kepada empat aspek iaitu aspek strategi, aspek program, aspek fasiliti dan kemudahan dan aspek pengetahuan. Dapatan kajian menunjukkan bahawa dua pemboleh ubah peramal iaitu aspek pengetahuan dan aspek fasiliti dan kemudahan merupakan peramal bagi pengurusan program latihan jurulatih fasa persediaan terhadap kepuasan atlet. Dua pemboleh ubah peramal yang lain iaitu aspek strategi dan aspek program bukan merupakan faktor dalam pengurusan program latihan jurulatih fasa persediaan terhadap kepuasan atlet.

Secara signifikan, aspek pengetahuan $[F(1,204)=63.210, p<$ $0.05]$ menyumbang sebanyak 23.7 peratus varians $\left(R^{2}=0.237\right)$ dalam kepuasan atlet bagi pengurusan program latihan jurulatih fasa persediaan. Selain daripada itu, aspek pengetahuan $(\beta=0.486, t(206)=7.950, p<0.05)$ merupakan petunjuk utama dalam kepuasan atlet bagi pengurusan program latihan jurulatih fasa persediaan. Kombinasi aspek pengetahuan $(\beta=$ $0.486, t(206)=7.950, p<0.05)$ dan aspek fasiliti dan kemudahan $(\beta=0.239, t(206)=2.413, p<0.05)$ menambah sebanyak $(25.8-$ 23.7) peratus atau 2.1 peratus kepada varians $\left(R^{2}=0.258\right)$ dalam pemboleh ubah kriteria kepuasan atlet bagi pengurusan program latihan jurulatih fasa persediaan $[F(2,203)=35.262$, $p<0.05$ ]. Oleh yang demikian, hipotesis $\mathrm{H}_{03}$ bahawa tidak terdapat pengaruh yang signifikan antara pengurusan program latihan jurulatih fasa persediaan terhadap kepuasan atlet adalah ditolak. Terdapat dua pemboleh ubah peramal yang signifikan iaitu aspek pengetahuan dan aspek fasiliti dan kemudahan.

Berdasarkan Jadual 4, pemboleh ubah kriteria dalam kajian ini ialah kepuasan atlet, manakala pemboleh ubah peramal pula ialah pengurusan program latihan jurulatih dalam kalangan atlet bagi fasa pertandingan. Fasa pertandingan ini dibahagikan kepada empat aspek iaitu aspek strategi, aspek program, aspek fasiliti dan kemudahan dan aspek pengetahuan. Hasil daripada analisis yang dijalankan, dapatan kajian menunjukkan bahawa secara signifikan satu pemboleh ubah peramal iaitu aspek program $(\beta=0.520, t(206)=$ $8.700, p<0.05)$, merupakan faktor utama pengurusan program latihan jurulatih fasa pertandingan terhadap kepuasan atlet. Hanya satu pemboleh ubah peramal sahaja menyumbang sebanyak 27.1 peratus $(r=0.520)$ perubahan varians dalam kepuasan atlet $[F(1,204)=75.694$, $p<0.05]$. 


\section{Jadual 4}

Analisis Regresi Stepwise Pengurusan Program Latihan Jurulatih Fasa Pertandingan Terhadap Kepuasan Atlet

\begin{tabular}{lccc}
\hline $\begin{array}{l}\text { Pengurusan Program Latihan Jurulatih } \\
\text { Fasa Pertandingan }\end{array}$ & $\beta$ & $t$ & $p$ \\
\hline Aspek Program & 0.520 & 8.700 & 0.000 \\
Maklumat : & & & \\
Aspek Program: & & & \\
${ }^{*} p<0.05$ & & \\
$R^{2}=0.271$ & & \\
$\mathrm{AR}^{2}=0.267$ & & \\
$F=75.694$ & & \\
$p=0.000$ & & \\
\hline $\mathrm{n}=206$ & &
\end{tabular}

Oleh sebab yang demikian, hipotesis $\mathrm{H}_{\mathrm{o} 4}$ bahawa tidak terdapat pengaruh yang signifikan antara pengurusan program latihan jurulatih fasa pertandingan terhadap kepuasan atlet secara keseluruhannya adalah ditolak. Terdapat satu pemboleh ubah peramal yang signifikan iaitu aspek program.

\section{Jadual 5}

Analisis Regresi Stepwise Pengurusan Program Latihan Jurulatih Fasa Transisi Terhadap Kepuasan Atlet

\begin{tabular}{llll}
\hline $\begin{array}{l}\text { Pengurusan Program Latihan Jurulatih } \\
\text { Fasa Transisi }\end{array}$ & $\beta$ & $T$ & $p$ \\
\hline Aspek Program & 0.526 & 8.834 & 0.000 \\
Maklumat : & & & \\
Aspek Program: & & & \\
${ }^{*} p<0.05$ & & \\
$R^{2}=0.277$ & & \\
$\mathrm{AR}^{2}=0.273$ & & \\
$F \quad=78.034$ & & \\
$p \quad=0.000$ & & \\
\hline $\mathrm{n}=206$ & &
\end{tabular}

Berpandukan Jadual 5, pemboleh ubah kriteria dalam kajian ini adalah kepuasan atlet, manakala pemboleh ubah peramal pula adalah pengurusan program latihan jurulatih bagi fasa transisi. 
Fasa transisi ini dibahagikan kepada empat aspek iaitu aspek strategi, aspek program, aspek fasiliti dan kemudahan dan aspek pengetahuan. Dapatan kajian menunjukkan bahawa secara signifikan satu pemboleh ubah peramal iaitu aspek program $(\beta=0.526, t(206)=$ $8.834, p<0.05)$, merupakan faktor utama pengurusan program latihan jurulatih fasa transisi terhadap kepuasan atlet. Hanya satu pemboleh ubah peramal sahaja menyumbang sebanyak 27.7 peratus $(r=0.526)$ perubahan varians dalam kepuasan atlet $[F(1,204)=78.034, p<0.05]$.

Oleh yang demikian, hipotesis $\mathrm{H}_{05}$ bahawa tidak terdapat pengaruh yang signifikan antara pengurusan program latihan jurulatih fasa transisi terhadap kepuasan atlet secara keseluruhannya adalah ditolak. Terdapat satu pemboleh ubah peramal yang signifikan iaitu aspek program.

\section{Perbincangan}

Pengurusan bermakna proses perancangan, penyusunan kerja, kepimpinan dan pengawalan, daya usaha anggota organisasi untuk mencapai matlamat yang ditentukan dalam konteks organisasi yang terlibat dengan penyediaan aktiviti, produk atau perkhidmatan sukan dan kecergasan (Chelladurai, 1999). Sementara itu, program latihan ialah satu tatacara, prosedur atau panduan yang dihasilkan oleh jurulatih bagi melatih atlet dalam satu tempoh tertentu. Oleh hal yang demikian, pengurusan program latihan dapat dinyatakan sebagai satu proses yang dirancang oleh jurulatih untuk melatih atlet di bawah kendaliannya dalam satu tempoh yang tertentu. Proses ini bermula dari fasa persediaan, fasa pertandingan dan fasa transisi. Terdapat empat aspek yang dikaji yang berdasarkan pengurusan program latihan yang merangkumi ketiga-tiga fasa ini, aspek-aspek tersebut ialah aspek program latihan, aspek strategi, aspek fasiliti dan kemudahan dan aspek pengetahuan jurulatih.

Sementara itu, dalam penyelidikan ini, dapatan kajian menunjukkan bahawa tidak terdapat perbezaan dalam fasa persediaan, fasa pertandingan dan fasa transisi serta keseluruhan fasa pengurusan program latihan jurulatih berdasarkan jantina atlet. Dapatan kajian ini menunjukkan bahawa atlet lelaki dan perempuan memerlukan keempat-empat aspek iaitu aspek program latihan, aspek strategi, aspek fasiliti dan kemudahan serta aspek pengetahuan jurulatih dalam mengharungi ketiga-tiga fasa. Keperluan semua aspek ini adalah bertepatan dengan saranan oleh Bompa (1999) bahawa faktor langsung dan faktor sokongan sangat mempengaruhi sistem latihan 
seseorang jurulatih. Kenyataan ini sama dengan cadangan Wee Eng Hoe (2006) iaitu bagi mengelakkan atlet menjadi bosan aspek seperti kemahiran, taktikal dan teknikal harus diberikan perhatian oleh para jurulatih bagi meningkat kepuasan atlet. Dapatan kajian ini juga selari dengan dapatan kajian yang dilakukan oleh Park et al. (2006) yang mendapati atlet lelaki dan wanita berpuas hati terhadap program latihan yang dikendalikan oleh jurulatih mereka. Atlet berpuas hati terhadap kemudahan sukan, kemampuan teknikal jurulatih (aspek pengetahuan), kaedah latihan (aspek program latihan) dan gaya kepimpinan jurulatih terutamanya dimensi maklum balas positif. Selain daripada itu, dapatan ini dikukuhkan lagi oleh Mohd Faithal (2006) yang menekankan bahawa pengetahuan dan pengalaman jurulatih amat membantu keefisienan jurulatih sehingga menjadikan sesi latihan menarik, tidak membosankan, melibatkan semua peserta dan mencapai objektif yang disasarkan.

Sementara itu, dapatan kajian ini juga mendapati bahawa terdapat hubungan antara pengurusan program latihan jurulatih dengan kepuasan atlet. Keempat-empat aspek yang dinyatakan dalam ketiga-tiga fasa program latihan mempunyai hubungan. Dapatan ini mengukuhkan lagi dapatan kajian oleh Greenleaf et al. (2001); Gibbons et al. (2003); Park et al. (1999) dan kenyataan Bompa (1999) serta Mohd Faithal (2006) yang menyatakan aspek personaliti dan pengetahuan jurulatih, fasiliti dan kemudahan sukan dapat meningkatkan kepuasan dan prestasi atlet.

Selain daripada itu, dapatan kajian ini juga menunjukkan terdapat hubungan yang positif antara keseluruhan pengurusan program latihan jurulatih dengan kepuasan atlet. Sementara itu, dapatan kajian juga mendapati bahawa terdapat hubungan yang positif antara ketiga-tiga fasa iaitu fasa persediaan, fasa pertandingan dan fasa transisi dalam pengurusan program latihan jurulatih dengan kepuasan atlet. Selain daripada itu, dapatan kajian juga mendapati terdapat hubungan antara keempat-empat aspek iaitu aspek program latihan, aspek strategi, aspek fasiliti dan kemudahan sukan serta aspek pengetahuan dalam ke tiga-tiga fasa mempunyai hubungan dengan kepuasan atlet.

Dapatan kajian ini selari dengan pandangan Greenleaf et al. (2001) dan Frontiera (2006) yang menyatakan jurulatih harus merancang aktiviti yang sesuai dan dapat memuaskan hati atlet agar atlet tidak merasa bosan dan atlet dapat mengekalkan tahap kecergasan mereka. Dapatan ini menunjukkan bahawa atlet memerlukan kesemua aspek 
dalam ketiga-tiga fasa pengurusan program latihan jurulatih bagi memuaskan hati mereka berdasarkan mereka adalah atlet MSSM, SUKMA dan negara yang sentiasa memerlukan pengetahuan (Sains Sukan) dan strategi dari jurulatih bagi meningkatkan pencapaian sama ada individu atau berpasukan, memerlukan program latihan yang sesuai dengan acara yang mereka ceburi bagi meningkatkan kecergasan, memerlukan fasiliti dan kemudahan agar pelaksanaan sesi latihan lebih kondusif kerana mereka selalunya bertanding di peringkat kebangsaan dan antarabangsa yang kompetitif dan memudahkan mereka membuat latihan praktikal dan simulasi sesuai dengan kejohanan yang disertai. Untuk meningkatkan kepuasan dan pencapaian, atlet seharusnya mendapatkan maklumat yang tepat dari jurulatih dan bersesuaian dengan Greenleaf et al. (2001) yang menyatakan kegagalan atlet pada Temasya Olimpik Musim Panas 1996 dan Musim Sejuk 1998 adalah disebabkan tidak mendapat maklumat atau pengetahuan yang berkaitan dengan teknikal dari jurulatih, latihan yang berlebihan dan perubahan taktikal yang dilakukan oleh jurulatih semasa kejohanan.

Selain daripada itu, Martens (1990) juga menekankan bahawa terdapat lima faktor yang harus diberi tumpuan oleh jurulatih iaitu program latihan, gaya kepimpinan yang digemari atlet dan strategi semasa melatih atlet. Park et al. (2006) pula menyatakan bahawa atlet olahraga Korea Selatan berpuas hati terhadap program latihan jurulatih dan kemampuan teknikal jurulatih. Dapatan kajian ini juga sejajar dengan dapatan kajian oleh Frontiera (2006) dan pandangan Ithnin (2005) yang menyatakan jurulatih yang mempunyai kemahiran dan pengetahuan dalam bidang Sains Sukan dapat mengenal pasti dan meningkatkan pencapaian atlet yang dilatihnya. Manakala Cakioglu (2005) juga sependapat dengan Frontiera (2006) dan Ithnin (2005) yang menyatakan jurulatih yang kekurangan ilmu pengetahuan Sains Sukan menyebabkan atlet kurang berpuas hati dan memberi kesan terhadap prestasi mereka. Sementara Mallet (2003) pula menyarankan jurulatih perlu mempunyai kemahiran dan ilmu pengetahuan yang mencukupi bagi meningkatkan prestasi atlet dalam bidang sukan yang mereka ceburi sama ada sukan individu mahupun sukan berpasukan.

Dapatan kajian ini juga menunjukkan bahawa dua pemboleh ubah peramal iaitu fasa transisi dan fasa persediaan merupakan peramal bagi pengurusan program latihan jurulatih terhadap kepuasan atlet. Pemboleh ubah peramal yang lain iaitu fasa pertandingan bukan merupakan faktor dalam pengurusan program latihan jurulatih 
terhadap kepuasan atlet. Sementaraitu, dapatan kajianjuga mendapati bahawa dua pemboleh ubah peramal iaitu aspek pengetahuan dan aspek fasiliti dan kemudahan merupakan peramal bagi pengurusan program latihan jurulatih fasa persediaan terhadap kepuasan atlet. Sementara aspek program latihan merupakan faktor dan peramal utama pengurusan program latihan jurulatih fasa pertandingan dan fasa transisi terhadap kepuasan atlet.

Oleh yang demikian, dapatan kajian ini menunjukkan bahawa atlet dari kedua-dua buah sekolah iaitu SSBJ dan SSBP mengehendaki jurulatih memberikan fokus kepada kedua-dua fasa ini kerana fasa ini merupakan fasa yang penting sebelum dan selepas sesuatu pertandingan dijalankan. Justeru itu, perkara yang berkaitan dengan aspek ilmu pengetahuan jurulatih seperti tunjuk ajar, maklumat baharu, latihan mental yang dipraktikkan dan respons setiap kali selesai latihan harus diberikan penekanan semasa fasa persediaan dilaksanakan. Begitu juga dengan pengurusan aspek fasiliti dan kemudahan seperti peralatan yang mencukupi dan terkini, dan sesuai dengan perancangan dan jenis latihan serta jenis acara yang disertai oleh atlet, dan yang amat mustahak ialah penggunaan kamera video dan teknologi terkini yang dapat mengenal pasti kekuatan dan kelemahan atlet semasa fasa persediaan ini dilaksanakan agar setiap kelemahan dapat diperbaiki dan prestasi atlet dapat ditingkatkan serta memberi dorongan kepada atlet untuk berusaha lebih gigih lagi. Penggunaan teknologi membolehkan atlet melihat pergerakan mereka semasa latihan dan dalam masa yang sama, atlet dan jurulatih juga dapat mengenal pasti kelemahan dan kekuatan dengan semerta.

Sementara itu, bagi pengurusan aspek program untuk fasa persediaan, beberapa perkara harus diberi tumpuan, antaranya jangka masa latihan yang perlu atlet lakukan terutamanya semasa melakukan latihan secara individu tanpa panduan dari jurulatih kerana selalu pada fasa ini, atlet diberikan satu modul program latihan yang harus dilakukan secara konsisten bagi mengekalkan tahap kecergasan diri. Selain daripada itu, program yang dirancang harus mengandungi pelbagai aktiviti agar atlet tidak bosan (Frontiera, 2006; Cakioglu, 2005; Mohd Faithal, 2006), mengingatkan atlet tentang faktor keselamatan, dan akhirnya latihan harus dirangka dari aktiviti yang mudah dan ringan dan ditingkatkan secara progresif bagi mengelakkan kecederaan yang dialami atlet. Berdasarkan (Frontiera, 2006; Greenleaf et al., 2001; Gibbons et al., 2003; Cakioglu, 2005; Ithnin, 2005), jurulatih harus mempunyai kemahiran dan ilmu pengetahuan dalam Sains Sukan. Saranan dan cadangan ini bertujuan agar atlet 
diberikan bantuan yang maksimum ketika fasa pertandingan tanpa meminggirkan fasa transisi dan fasa persediaan. Ketiga-tiga fasa ini amat penting buat atlet dalam mencapai tahap kepuasan berdasarkan matlamat yang telah ditetapkan. Faktor ini menyebabkan atlet tidak dapat mengekalkan prestasi mereka dan terpaksa bermula dari transisi dan diikuti pula fasa persediaan. Oleh yang demikian, para jurulatih harus memberi fokus bukan sahaja kepada pengurusan program bagi fasa pertandingan tetapi juga kepada fasa persediaan dan fasa transisi.

Sementara itu, dapatan kajian juga selari dengan saranan dan cadangan Frontiera (2006), Greenleaf et al. (2001), Gibbons et al. (2003), Gert et al. (2007), Frey, Czech, Kent and Johnson (2007), Mohd Faithal (2006) dan Bompa (1999), berkaitan sistem latihan dan faktor yang mempengaruhi kualiti latihan jurulatih. Berdasarkan dapatan kajian ini, terdapat beberapa faktor sokongan yang mempengaruhi sistem latihan iaitu aspek fasiliti dan kemudahan, aspek program latihan, aspek pengetahuan dan personaliti jurulatih. Dapatan ini juga mengesahkan pandangan Bompa (1999) yang menyatakan kualiti sistem latihan bergantung kepada dua perkara iaitu faktor langsung dan faktor sokongan kerana kedua-dua faktor ini mempunyai hubungan atau saling berkait. Walaupun begitu, dapatan kajian menunjukkan aspek program latihan adalah faktor dominan bagi fasa transisi dan fasa pertandingan dalam pengurusan program latihan jurulatih manakala aspek pengetahuan dan fasiliti dan kemudahan adalah aspek yang dominan bagi fasa persediaan. Dapatan ini membuktikan bahawa aspek-aspek dalam kajian ini mempunyai pengaruh seperti yang dinyatakan oleh Bompa (1999) terhadap sistem latihan.

\section{Rumusan}

Dapatan kajian menunjukkan bahawa aspek program latihan, aspek pengetahuan dan aspek fasiliti dan kemudahan merupakan peramal pengurusan program latihan kepada kepuasan atlet. Oleh yang demikian, pihak yang berkaitan seperti jurulatih atau ahli akademik Sains Sukan yang pakar harus dijemput dan merangka program latihan yang terkini selaras dengan perkembangan Sains Sukan era globalisasi tanpa melupakan aspek fasiliti dan kemudahan dan dikongsi bersama melalui persidangan, bengkel ataupun seminar. Teknologi moden dalam fasiliti dan kemudahan harus digunakan oleh jurulatih dan atlet dengan cuba mengurangkan pendekatan secara tradisional. 
Selain daripada itu, bagi mendapatkan dapatan kajian yang lebih kukuh lagi, dicadangkan kajian pada masa akan datang, penyelidik tidak hanya menggunakan subskala yang terpilih sahaja. Disarankan penyelidik akan datang menggunakan dan menambah aspek-aspek yang bersesuaian dalam Pengurusan Program Latihan Jurulatih (PPLJ). Cadangan ini disarankan kerana pengkaji akan memperoleh satu dapatan yang menyeluruh dan dapat mengenal pasti pemboleh ubah peramal yang dominan dalam kajian yang dilaksanakan nanti.

\section{Rujukan}

Abd Hair Awang, Azimi Hamzah, Jegak Uli, Asma Ahmad, \& Rahmah Ismail. (2006). Program latihan kemahiran: Perbandingan kos, kebolehpasaran dan pendapatan pelatih. International Journal of Management Studies, 13(1), 212-244.

Anuar Din. (2010). Gaya kepimpinan, kepuasan kerja dan pengurusan program latihan jurulatih terhadap kepuasan atlet sekolah sukan (Tesis doktor Falsafah yang tidak diterbitkan). Sekolah Pendidikan dan Pembangunan Sosial, Universiti Malaysia Sabah, Kota Kinabalu, Sabah.

Anuar Din \& Dolorine Miting. (2013). Pengaruh gaya kepimpinan jurulatih terhadap kepuasan atlet di sekolah sukan Malaysia. Atikan: Jurnal Kajian Pendidikan, 3(2), 195-209.

Bompa, T. O. (1999). Periodization: Theory and methodology of trainin. (4th ed.). Champaign, Illinois: Human Kinetics.

Cakioglu, A. (2003). Leadership and satisfaction in soccer: Examination of congruence and players' position (Master thesis yang tidak diterbitkan). Department of Physical Education and Sport: Middle East Technical University.

Chelladurai, P. (1984). Discrepancy between preferences and perceptions of leadership behavior and satisfaction of athletes in varying sport. Journal of Sport Psychology, 6, 27-41.

Chelladurai, P. (1999). Human resource management in sport and recreation. Champaign, Illinois: Human Kinetics.

Chua Yan Piaw. (2006). Kaedah dan statistik penyelidikan buku 1: Kaedah penyelidikan. Kuala Lumpur: Mc Graw Hill.

Davies, M. J., Bloom, G.A., \& Salmela, J. H. (2005). Job satisfaction of accomplished male university basketball coaches: The Canadian context. International Journal of Sport Psychology, 36, 173-192. 
Duda, J. L., \& Nicholls, J. G. (2006). The interaction of goal orientation and stage of change on exercise behavior in college students. Journal of Sport Behavior, 38, 95-126.

Frey, M., Czech, D. R., Kent, R. G., \& Johnson, M. (2006). An exploration of female athletes experiences and perceptions of male and female coaches. The Sport Journal, 9, 4.

Frontiera, J. (2006). The relationship between leadership, efficacy belief, and performance among boys' high school basketball player (Tesis master yang tidak diterbitkan). West Virginia University, USA.

Gay, L. R., \& Airasian, P. (2003). Educational research: Competencies for analysis and applications (7th ed.). New Jersey: Pearson Education.

Gert, B. V., Tanja, C., Filip, B., Jeroen, V., Wouter, G., \& Marten, V. (2007). Influence coaches behavior on the performance of top sport student in individual and team sports. Proceedings Universiade Bangkok 2007, FISU Cenference, 24 ${ }^{\text {th }}$, 238-242.

Gibbons, T., McConnel, A., Forster, T., Riewald, S. T., \& Peterson, K. (2003). Reflections on success: US Olympians describe the success factors and obstacles that most influenced their Olympic development (Vol. Report phase II). Colorado Springs: United States Olympic Committee.

Greenleaf, C., Gould, D., \& Dieffenbach, K. 2001. Factors influencing Olympic performance: Interviews with Atlanta and Nagano U.S. Olympians. Journal of Applied Sport Psychology, 13, 154-184.

Hamidreza Saybani. (2013). Structural Equation Modelling analysis of the relationship between transformational leadership style of coaches, sport commitment, and athletes' satisfaction among Iranian high school football players. Unpublished Doctor of Philosophy Thesis. Universiti Putra Malaysia, Serdang, Selangor.

Ithnin Mahadi. (2005, Mac 10). Jurulatih perlu ambil kira Sains Sukan. Berita Harian, hlm. 37.

Jin Ho Choi. (2006). The relationship among transformational leadership, organizational outcomes, and service quality in five major NCAA conferences ( Tesis master yang tidak diterbitkan). Texas A\&M University, USA, Texas.

Krejcie, R. V., \& Morgan, D. W. (1970). Determining sample size for research activities. Educational and Psychological Measurement, 30, 608 .

Mallett, C. J., \& Hanrahan, S. J. (2004). Elite athletes: Why does the fire burn so brightly? Psychology of Sport and Exercise, 5, 183-200.

Martens, R. (1990). Successful coaching. Champaign, Illinois: Leisure Press. 
Mohd Faithal Hassan. (2006). Pengurusan kejurulatihan. Dlm. Mohd Salleh Aman (Penyt). Pengurusan Sukan: Aplikasinya di Malaysia. Kuala Lumpur: Penerbit Universiti Malaya.

Mohd Najib Gaffar. (2000). Penyelidikan pendidikan. Skudai, Johor: Universiti Teknologi Malaysia.

Mohd Salleh Aman. (2005). Asas pengurusan sukan. Kuala Lumpur: Penerbit Universiti Malaya.

Young-Jun Park, DeSchriver, D., Bestmann, L., \& Jon “YeanSub" Lim. (2008). Satisfaction levels of elite track and field athletes in South Korea. The Sport Journal, 02-11.

Reimer, H. A., \& Toon, K. (2001). Leadership and satisfaction in tennis: Examination of congruence, gender and ability. Research Quarterly for Exercise and Sport, 72 (3), 243-256.

Riemer, H. A., \& Chelladurai, P. (1998). Development of the athlete satisfaction questionnaire (ASQ). Journal of Sport Exercise Psychology, 20, 127-156.

Robbins, J. E, \& Rosefeld, L. B. (2001). Athletes' perceptions of social support provided by their head coach, assistant coach, and athletic trainer, pre-injury and during rehabilitation. Journal of Sport Behaviour, 24, 277-298.

Serpa, S., Pataco, V., \& Santos, F. (1991). Leadership patterns in handball international competition. International Journal of Sport Psychology, 22 (1), 79-89.

Shaharudin Abd Aziz. (2005). Perkaitan antara matlamat dan stail kepimpinan dengan pencapaian atlet Sukma Negeri Perak di Kejohanan Sukma 2004. eWacana Penyelidikan UPSI, 13.

Wee Akina Sia Seng Lee \& Shabeshan Rengasamy. (2014). Gaya kepimpinan jurulatih yang diminati atlet-atlet sekolah menengah di Malaysia berasaskan jantina. Jurnal Kepimpinan Pendidikan, 1(1), 65-74.

Wee Eng Hoe. (2006). Tanggungjawab jurulatih dalam pengurusan pasukan dan atlet. Dlm. Mohd Salleh Aman (Penyt.). Pengurusan Sukan: Aplikasinya di Malaysia. Kuala Lumpur: Penerbit Universiti Malaya. 